\title{
Towards the Synthesis of Proanthocyanidins: Half a Century of Innovation
}

Authors

Affiliations
Daneel Ferreira ${ }^{1,2}$, Christina M. Coleman ${ }^{1}$

${ }^{1}$ Department of Pharmacognosy, School of Pharmacy, University of Mississippi, University, MS, USA

2 Research Institute of Pharmaceutical Sciences, School of Pharmacy, University of Mississippi, University, MS, USA
Key words

- synthesis

proanthocyanidins

- procyanidins

- profisetinidins

- flavan-3,4-diols

- catechins

- condensed tannins received Dec. 22, 2010

revised February 11, 2011

accepted February 14, 2011

Bibliography

Dol http://dx.doi.org/

10.1055/s-0030-1270908

Published online March 16,

2011

Planta Med 2011; 77:

1071-1085 @ Georg Thieme

Verlag KG Stuttgart - New York .

ISSN 0032-0943

\section{Correspondence}

\section{Dr. Daneel Ferreira}

Department of Pharmacognosy

School of Pharmacy

University of Mississippi

P. O. Box 1848

University, MS 38677

USA

Phone: + 16629157026

Fax: + 16629156975

dferreir@olemiss.edu

\section{Abstract \\ $\nabla$}

Results emanating from the synthesis of proanthocyanidins played a crucial role in defining the constitution, regiochemistry, and absolute configuration of this complex but fascinating group of plant secondary metabolites. The initial efforts, commencing in 1966, were focused on structure elucidation of, especially, the procyanidins, profisetinidins, and prorobinetinidins. However, over the past 12 years the emphasis has shifted to the synthesis of the bioactive procyanidins and some

\section{Introduction}

$\nabla$

The first reports dealing with the isolation and structure elucidation of naturally occurring proanthocyanidins (syn. condensed tannins) were documented in the early 1960s. These early contributions and achievements by pioneers like Forsyth and Roberts, Drewes and Roux, Freudenberg and Weinges, Swain, Geissman, Mayer, Seshadri, Pelter, Brown, and several others were covered in a comprehensive 1972 review [1]. The accuracy of the initial structural assignments needs to be judged in terms of the sophistication of the instrumentation available at the time. Thus, it soon became evident that the complexity of a proanthocyanidin structure would require utilization of the full array of tools at the disposal of the natural product chemist in order to address the subtleties of the structure elucidation of this fascinating class of natural products. Prevalent among these methods was the potential of synthetic protocols to complement physical methods like nuclear magnetic resonance (NMR) and circular dichroism (CD) spectroscopy, and mass spectrometric (MS) measurements. Therefore, it came as no surprise that the first synthesis of a procyanidin derivative was attempted as early as 1966 [2], such a synthesis being based on the premise of their derivatives at a scale that would permit assessment of their pharmacological properties. With a few exceptions, the vast majority of these synthetic protocols involve the formation of the interflavanyl bond by acid/Lewis acid activation at C-4 of a flavan-3,4-diol or its equivalent, and subsequent trapping of the incipient $\mathrm{C}-4$ carbocation by the nucleophilic centers of a flavan-3-ol (catechin). This review represents the first comprehensive chronicle depicting the development of the subject of proanthocyanidin synthesis. that proanthocyanidins were biosynthetically formed via the condensation of a flavan-3,4-diol and a flavan-3-ol as the incipient electrophile and nucleophile, respectively $[3,4]$. The development of synthetic methods for the production of proanthocyanidins was initially used as an analytical tool $[2,5-14]$ in the quest to assign their constitution and absolute configuration. The emphasis recently shifted to synthesis as a means to access sufficient amounts of free phenolic material in order to probe the bioactivity and pharmacological effects of, especially, the procyanidins [15]. Herein we present a concise review of the evolution of proanthocyanidin synthetic methodologies beginning with the pioneering efforts of Geissman and Yoshimura [2] and concluding with the current state-of-the-art protocols supported by modern day chromatographic and spectroscopic/spectrometric techniques.

\section{Discussion \\ $\nabla$}

The first synthesis of a procyanidin derivative $\mathbf{3}$ is credited to the pioneering work of Geissman and Yoshimura [2]. Mild acid-catalyzed condensation of the leucocyanidin (flavan-3,4-diol) analogue 1 and free phenolic catechin (2) (a flavan-3-ol) fol- 
lowed by methylation and acetylation, afforded the procyanidin derivative 3 ( $\odot$ Fig. 1). Structure elucidation of 3 was based on ${ }^{1} \mathrm{H}$ NMR data acquired at $60 \mathrm{MHz}$ and hence not comprehensive. However, these results did demonstrate the feasibility of utilizing a flavan-3,4-diol and a flavan-3-ol as the extender and starter units, respectively, to synthetically access proanthocyanidins.

Weinges and his collaborators [5,6] utilized a Grignard-type coupling reaction between the 8-lithio derivative of catechin (5) and the taxifolin derivative 4 ( Fig. 2 ) to produce an intermediate 4hydroxyprocyanidin. Hydrogenolysis to reductively remove the 4-hydroxy group and the benzyl protecting group, and subsequent acetylation afforded the perceived procyanidin B-3 derivative 6.

The first synthesis of free phenolic procyanidins emanated from the work of Haslam and his collaborators $[7,8]$. Their approach (๑ Fig. 3) involved the generation of $4 \beta$-benzylthio-epicatechin (7) and $4 \alpha$-benzylthiocatechin (8) via acid-catalyzed thiolysis [9] of the procyanidin polymers of Salix caprea and Crataegus monogyna, respectively. Under acidic conditions, the 4-benzylthioethers $\mathbf{7}$ and $\mathbf{8}$ equilibrate with their C-4 carbocations $\mathbf{9}$ and $\mathbf{1 0}$, respectively. These reactive intermediates are subsequently trapped separately by catechin (2) to afford procyanidins B-1 (12) and B-3 (14), respectively, and by epicatechin (11) to give procyanidins B-2 (13) and B-4 (15), respectively. In contrast to the synthetic derivatives $\mathbf{3}$ and $\mathbf{6}$, the structures of procyanidins B-1 - B-4 were properly elucidated and shown to be identical to the naturally occurring analogues.

Our own work in the proanthocyanidin field commenced in the late 1960s in Bloemfontein, South Africa, when we turned to the investigation of the polyphenolic profile of the large variety of hardwood species in Southern Africa. The proanthocyanidin pool in these sources is dominated by 5-deoxy analogues, i.e., the profisetinidins and prorobinetinidins, and is of considerable com- plexity as far as heterogeneity of the interflavanyl bonds and configurational diversity of the heterocyclic rings are concerned. Thus, it came as no surprise that the structures of the first profisetinidin-type tri- 16 [10] and tetra-flavonoid 17 [11] ( Fig. 4) of undefined absolute configuration were incorrectly assigned. This prompted us to embark on a systematic program of synthesis of, especially, the profisetinidins and prorobinetinidins [12], knowing well that others would follow suit as far as the synthesis of the other classes of proanthocyanidins, especially the procyanidins, was concerned.

Our approach, similar to that of Geissman and Yoshimura [2], was based on the utilization of a flavan-3,4-diol or its equivalent 18 as a potential C-4 electrophile 19 and a flavan-3-ol, e.g., catechin (2), as nucleophile to form the interflavanyl bond ( $\nabla$ Fig. 5 ) in, e.g., a $(4 \rightarrow 8)$-linked proanthocyanidin 20 . Such an approach was feasible because of the commercial availability of the flavan-3-ol catechin (2) and the natural availability of three flavan-3,4-diols: fisetinidol-4 $\alpha$-ol (21) from Acacia mearnsii (Black Wattle), its enantiomer ent-fisetinidol-4 $\beta$-ol from Quebracho (Schinopsis spp.), and epioritin-4 $\beta$-ol (25) from Acacia auricultriformis [13].

Under mild aqueous acidic conditions, fisetinidol-4 $\alpha$-ol (21) and phloroglucinol (22) condensed to afford a mixture of fisetinidol$(4 \alpha \rightarrow 2)$-phloroglucinol (23) and fisetinidol-( $4 \beta \rightarrow 2)$-phloroglucinol (24) (๑ Fig. 6) [12,13]. Under similar conditions, epioritin$4 \beta$-ol (25) and phloroglucinol (22) exclusively gave the epioritin$(4 \beta \rightarrow 2)$-phloroglucinol adduct 26 , such selectivity being effected by the $\alpha$-axial 3-hydroxy group in a C-4 carbocationic intermediate of type 19 [12,13].

Subsequently, we focused on the application of a similar protocol to synthesize the naturally occurring profisetinidin-type biflavanoids that occur abundantly in the commercially important bark extract of Black Wattle. Thus, acid-catalyzed condensation of fisetinidol-4 $\alpha$-ol (21) and catechin (2) afforded a mixture of fiseti-<smiles>COc1cc(OC)c2c(c1)OC(c1ccc(OC)c(OC)c1)C(O)C2O</smiles>

Fig. 1 The first synthesis of a procyanidin derivative 3.

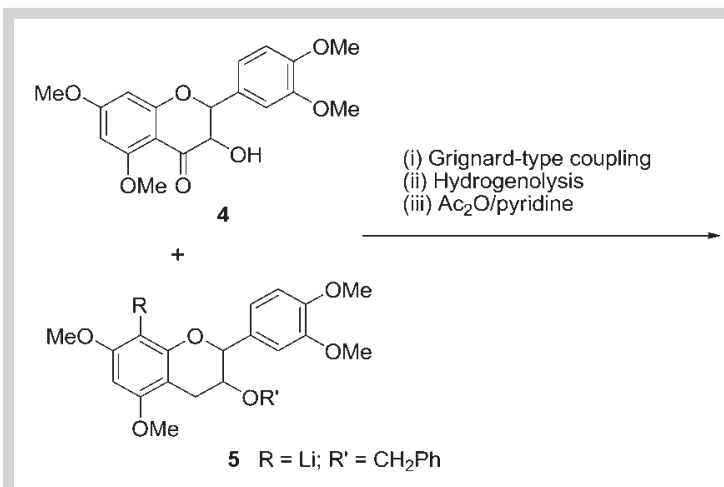

Fig. 2 Synthesis of procyanidin derivative 6 via a Grignard-type coupling. 

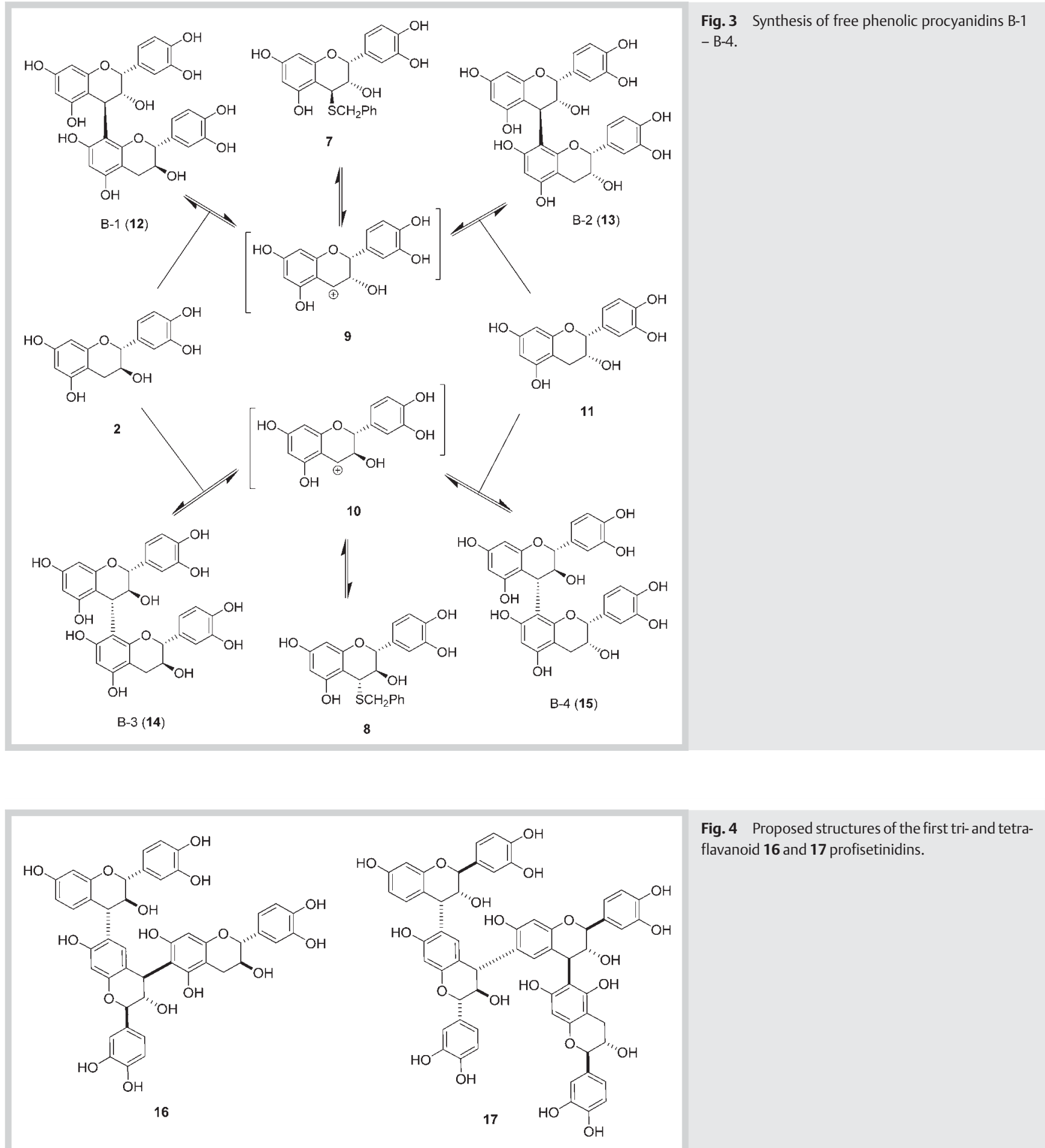

Fig. 4 Proposed structures of the first tri- and tetraflavanoid 16 and 17 profisetinidins.

nidol-( $4 \alpha \rightarrow 8)$-catechin (27), fisetinidol- ( $4 \beta \rightarrow 8)$-catechin (28), and fisetinidol- $(4 \alpha \rightarrow 6)$-catechin (29) ( Fig. 7) [14,15]. The structures of the two $(4 \rightarrow 8)$-linked analogues 27 and 28 were shown to be identical to the corresponding natural products from Black Wattle bark, with regards to both structure and absolute configuration. Although the fisetinidol- $(4 \beta \rightarrow 6)$-catechin (30) could not be identified in the initial work, its formation was confirmed in a subsequent study [16].

The protocol of acid-catalyzed condensation of a flavan-3,4-diol and a flavan-3-ol to effectively and predictably form the interflavanyl bond was extended to include the synthesis of a compre- hensive array of dimeric 5-deoxy proanthocyanidins. Flavan3,4-diols employed included: ent-fisetinidol-4 $\beta$-ol (ent-21) [15, 17], robinetinidol-4 $\alpha$-ol (31) [15], mopanol A (32) [18], guiboutinidol-4 $\alpha$-ol (33) [19], butiniflavan-4-ols (34) [20], cassiaflavan-4ols (35) [21], and epioritin-4 $\beta$-ol (25) and epimesquitol-4 $\beta$-ol (36) [22]. The flavan-3-ols employed included: catechin (2) [1517] and epicatechin (11) [15], gallocatechin and epigallocatechin (37 and 38) [20,21], and fisetinidol (39) and ent-epifisetinidol (40) [19] ( Fig. 8). It should be emphasized that the 5,7-dihydroxyflavan-3-ols, e.g., catechin (2), capture C-4 electrophiles originating from 5-deoxyflavan-3,4-diols, e.g., fisetinidol- $4 \alpha$-ol 

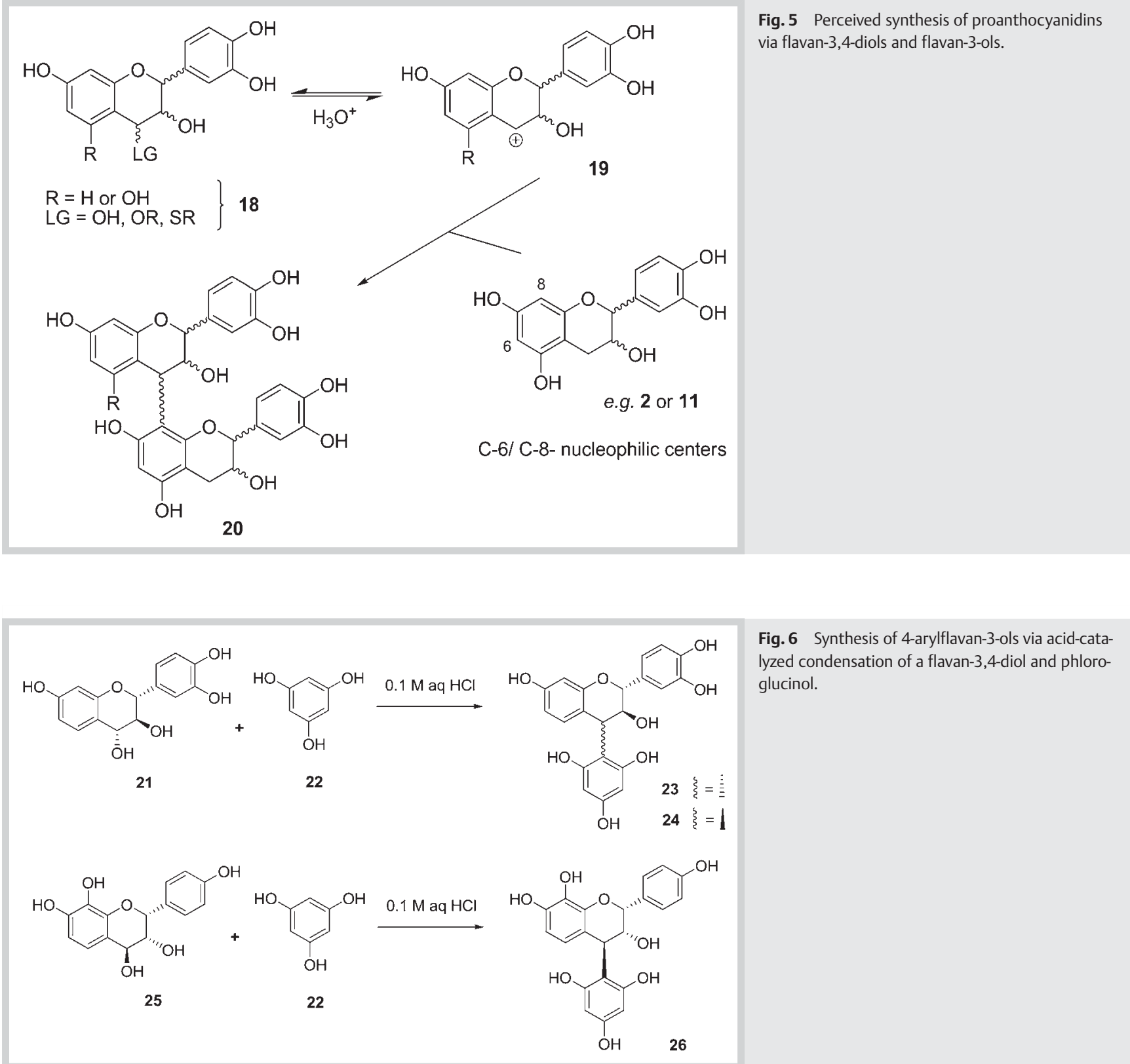

Fig. 6 Synthesis of 4-arylflavan-3-ols via acid-catalyzed condensation of a flavan-3,4-diol and phloroglucinol.
(21), at both C-6 and C-8. In contrast, 5-deoxyflavan-3-ols, e.g., fisetinidol (39), capture the same C-4 electrophile regioselectively at C-6.

Availability of the synthetic 4-arylflavan-3-ols generated as in - Fig. 6 permitted us to formulate a simple circular dichroic (CD) rule to define their absolute configuration at C-4 $[12,13,23,24]$. The rule was also applicable to the biflavanoids $[14,15]$ and has been used extensively to define the absolute configuration at C-4 (C-ring) of the full array of naturally occurring dimeric proanthocyanidins.

Having established the regiochemistry of the coupling between fisetinidol-4 4 -ol (21) and catechin (2) ( $\bullet$ Fig. 7), and in view of the coupling positions "defined" for the profisetinidin triflavanoid 16 from Colophospermum mopane, we next used the fisetinidol-( $4 \alpha \rightarrow 8)$ - and ( $4 \beta \rightarrow 8)$-catechins (27 and 28) ( Fig. 7) as nucleophiles to capture the $\mathrm{C}-4$ carbocation derived from fisetinidol-4 $\alpha$-ol (21) ( Fig. 9) [25, 26]. This culminated in the formation of four angular profisetinidin triflavanoids 41-44. These com- pounds were shown to be identical to the four analogues isolated from the heartwood of Black Wattle [27]. The CD data of the alltrans and all-cis analogues 41 and $\mathbf{4 4}$, respectively, were crucial to the assignment of the absolute configuration at C-4 of both the Cand I-rings of these compounds. The four triflavonoids in which the chain extender units were derived from ent-fisetinidol-4 $\beta$-ol were synthesized in a similar fashion and shown to be identical to the four naturally occurring analogues isolated from Rhus lancea [17]. Two of these structures are shown as 45 and 46 in - Fig. 10.

An interesting feature of the regiochemistry of the coupling process is that C- 6 of the phloroglucinol D-ring, rather than C- 6 of the resorcinol A-ring, of the biflavanoid $\mathbf{2 7}$ acted as the preferential nucleophilic center. This contrasted with the general belief of a "linear" condensation mode for the formation of profisetinidin triflavanoids [10]. In addition, the structure and absolute configuration of fisetinidol- $(4 \alpha \rightarrow 8)$-catechin-( $6 \rightarrow 4 \alpha)$-fisetinidol (41) were shown to be identical to the analogue from Colophosper- 


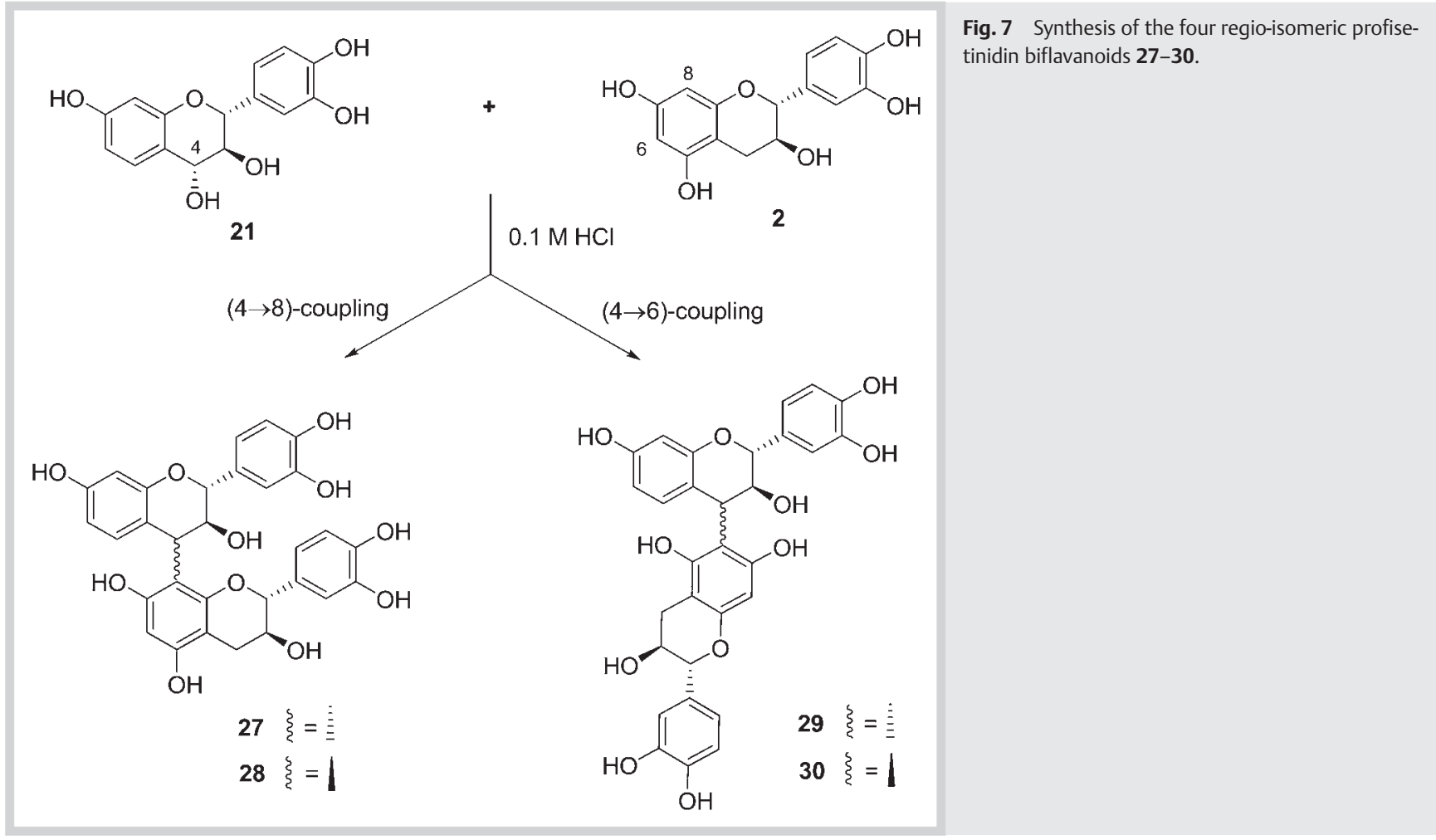<smiles>Oc1ccc2c(c1)O[C@H](c1cc(O)c(O)c(O)c1)[C@H](O)[C@H]2O</smiles><smiles>[R]c1cc([C@H]2C[C@H](O)c3ccc(O)cc3O2)ccc1O</smiles>

$34 \mathrm{R}=\mathrm{OH}$ $35 \mathrm{R}=\mathrm{H}$<smiles>Oc1ccc2c(c1)O[C@H](c1ccc(O)c(O)c1)C(O)C2</smiles>

$39 \xi=\vdots$

$40 \xi=1$<smiles>Oc1ccc2c(c1)O[C@H]1c3ccc(O)c(O)c3CO[C@H]1[C@H]2O</smiles>

32<smiles>[R]c1cc([C@H]2Oc3c(ccc(O)c3O)[C@@H](O)[C@H]2O)ccc1O</smiles>

36 立, $\mathrm{R}=\mathrm{OH}$

$25 \xi=$ I, R $=\mathrm{H}$<smiles>Oc1ccc([C@@H]2Oc3cc(O)ccc3[C@@H](O)[C@H]2O)cc1</smiles>

33<smiles>Oc1ccc2c(c1)O[C@H](c1cc(O)c(O)c(O)c1)[C@H](O)C2</smiles>

$\mathrm{OH}$

$37 \xi=1$

38 京
Fig. 8 Flavan-3,4-diols, flavan-4-ols, and flavan-3ols utilized in the synthesis of a comprehensive series of dimeric 5-deoxy proanthocyanidins. mum mopane that was assigned structure 16 [10]. This was a gratifying experience that also provided a solid foundation to further unravel the considerable complexities of the naturally occurring classes of proanthocyanidins with 5-deoxy extender and 5,7-dihydroxy starter flavanoid units.

At the tetraflavanoid level, the key issue was to define whether C6 of the A- or G-ring in a triflavanoid precursor of type 41 would be preferred in the chain extension process. In order to add the third fisetinidol/ent-fisetinidol structural moiety, we therefore used the four trimers $\mathbf{4 1 - 4 4}$ and their diastereoisomers, e.g., 45 and 46, synthesized by employing ent-fisetinidol-4 $\beta$-ol (ent-21) in an acid-catalyzed condensation with catechin (2). Utilization of the all-trans triflavanoid $\mathbf{4 1}$ with fisetinidol extender units afforded the all-trans tetraflavanoid 47 , with the third fisetinidol moiety regioselectively added to C-6 of the A-ring of precursor 41 ( Fig. 11) [28]. The same regioselectivity was observed when the synthetic triflavanoids $\mathbf{4 2 - 4 4}$ were subjected to the same treatment. The structures of the resulting four tetraflavanoids 


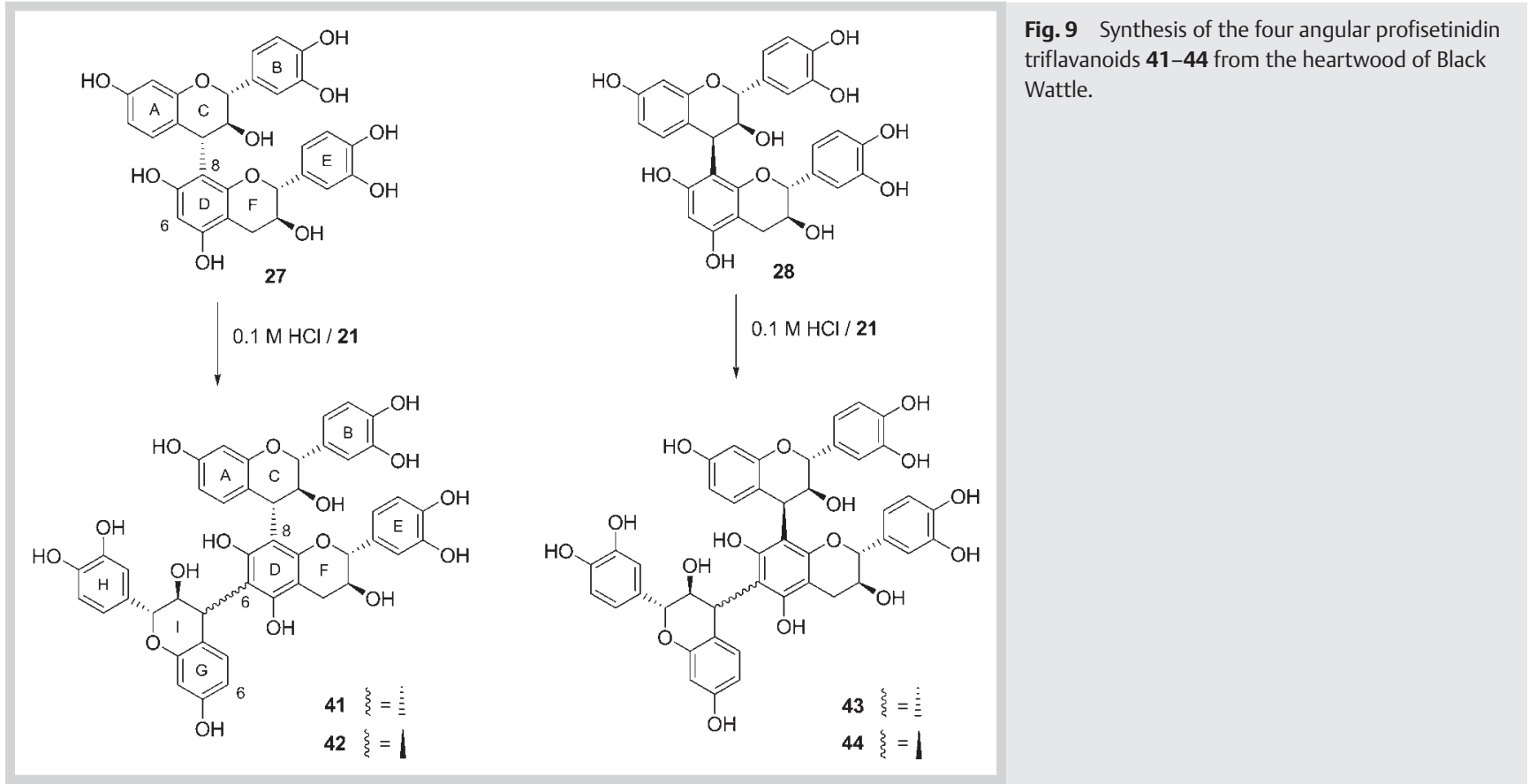<smiles>Oc1ccc2c(c1)O[C@H](c1ccc(O)c(O)c1)[C@@H](O)C2c1c(O)c([C@H]2c3ccc(O)cc3O[C@H](c3ccc(O)c(O)c3)[C@@H]2O)c(O)c2c1O[C@H](c1ccc(O)c(O)c1)C[C@H]2O</smiles>

were identical to the corresponding natural products from the heartwood of Black Wattle [28].

The four diastereoisomeric triflavanoids with ent-fisetinidol chain extender units, e.g., compounds 45 and 46, were similarly subjected to acid-catalyzed condensation with ent-fisetinidol$4 \beta$-ol. Again, the third ent-fisetinidol unit was added regioselectively at C-6 of the ABC moiety to produce four diastereoisomeric tetraflavanoids, e.g., 48 ( Fig. 11) [29]. The four synthetic com- pounds were shown to be identical to the four naturally occurring analogues obtained from Rhus lancea $[11,29]$. In addition, compound $\mathbf{4 8}$ was identical to the first tetraflavanoid that was assigned structure 17 almost fifteen years earlier.

This work dealing with the synthesis of the tri- and tetraflavanoids abundantly demonstrates the necessity of a synthetic approach in order to unequivocally assign the composition and absolute configuration of these complex compounds.

A range of catechin- $(4 \alpha \rightarrow 8)$ and $(4 \alpha \rightarrow 6)$-catechin procyanidin bi- and triflavanoids, as well as the first di- and trimeric procyanidins with $(4 \beta \rightarrow 8)$-interflavanyl linkages, could be accessed by replacing the 5-deoxyflavan-3,4-diols with a mixture of catechin- $4 \alpha$ - and $4 \beta$-ols (49) (leucocyanidins), using catechin (2) and epicatechin (11) as starter units. Some of these analogues are shown in $\odot$ Fig. 12 [15,30,31], e.g., all-trans-all- $(4 \alpha \rightarrow 8)$-linked procyanidin (50), catechin- $(4 \beta \rightarrow 8)$-epicatechin (51), and the alltrans trimer $\mathbf{5 2}$ with mixed regiochemistry.

When considering the synthesis of the biologically important procyanidins, it became evident early on that synthetic access would be hampered by the unavailability of 5-oxyflavan-3,4-diol-type precursors like $\mathbf{1}, \mathbf{7}, \mathbf{8}$, and 49 . Thus, we developed a<smiles>Oc1ccc2c(c1)O[C@H](c1ccc(O)c(O)c1)[C@@H](O)[C@H]2c1c(O)c2c(c([C@H]3c4ccc(O)cc4O[C@H](c4ccc(O)c(O)c4)[C@@H]3O)c1O)C[C@H](O)[C@H](c1ccc(O)c(O)c1)O2</smiles>

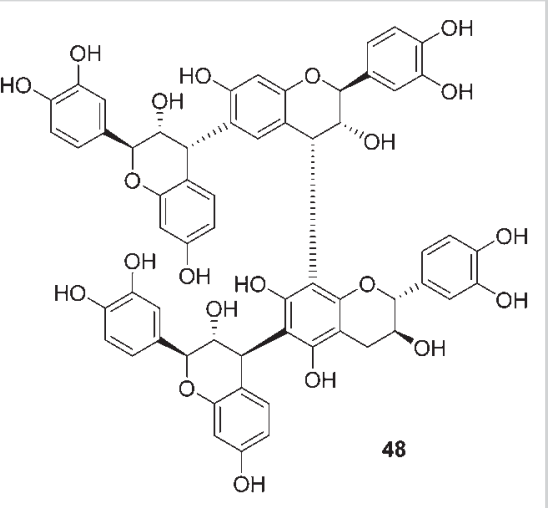

Fig. 11 Naturally occurring and synthetic profisetinidin-type tetraflavanoids. 

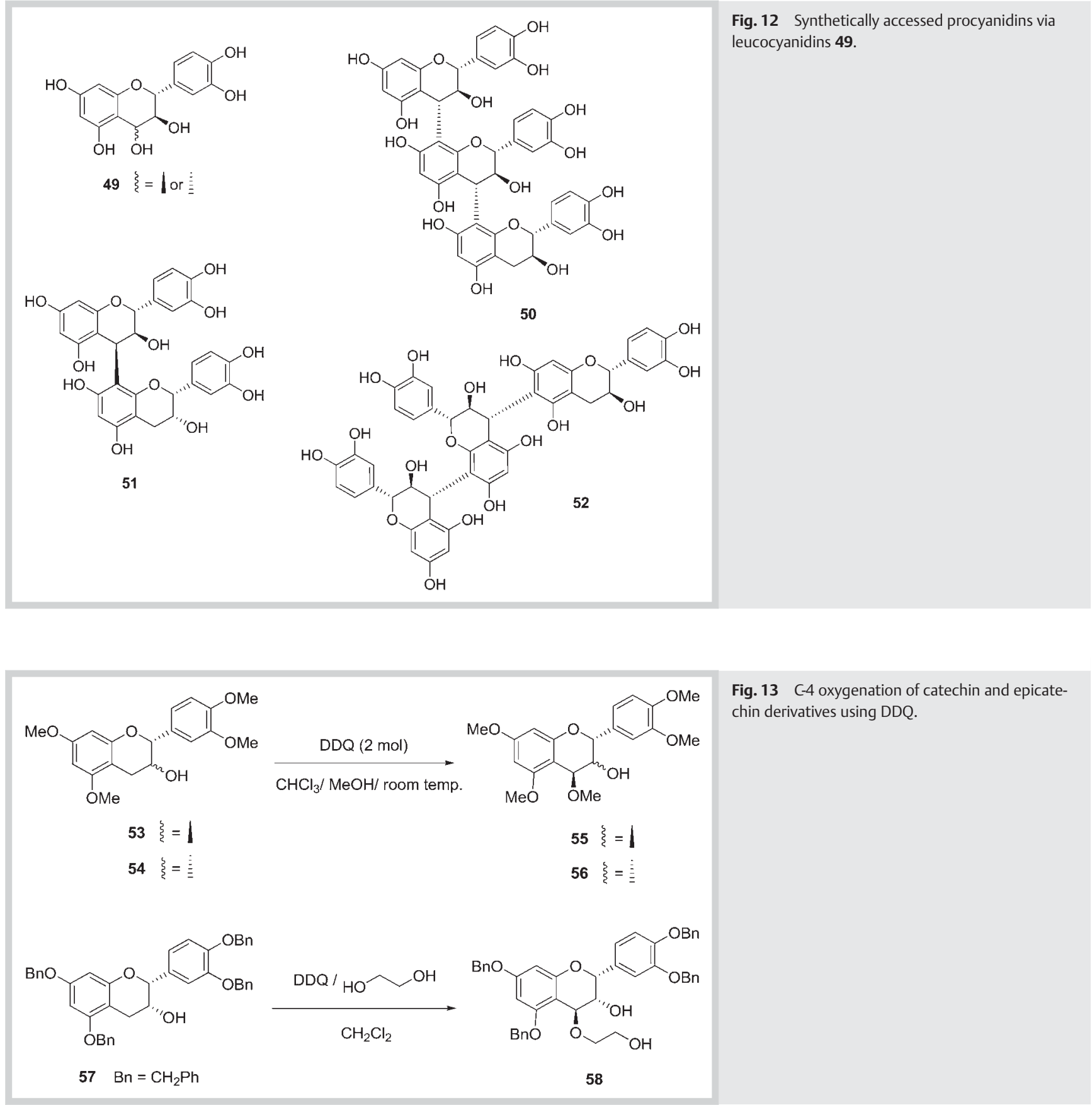

method to oxygenate the tetra- 0 -methyl ethers $\mathbf{5 3}$ and $\mathbf{5 4}$ of catechin (2) and epicatechin (11), respectively, in ca. 50\% yield using 2,3-dichloro-5,6-dicyano-1,4-benzoquinone (DDQ) in methanol ( Fig. 13) [32]. The 4-methoxyflavan-3-ols 55 and 56 could then serve as the extender units to procyanidins possessing both catechin and epicatechin moieties.

In order to improve the utility of the $\mathrm{C}-4$ oxygenated catechin and epicatechin derivatives towards the synthesis of free phenolic procyanidins, Kozikowski and his coworkers used the $O$-benzyl protected epicatechin derivative $\mathbf{5 7}$ and DDQ to synthesize the 4-O-(hydroxyethyl)flavan-3-ol analogue 58 ( Fig. 13) [33]. This reaction was performed using ethylene glycol in dichloromethane as the nucleophile in place of methanol in chloroform, as these conditions resulted in a cleaner reaction with a higher overall yield of the C-4 oxygenated product [34]. Following the requi- site synthetic manipulations, the free phenolic procyanidins were made readily available via mild deprotection using catalytic hydrogenation [33].

One of the complications of the formation of the interflavanyl bond in procyanidins under acidic conditions is the instability of this bond under the very conditions required for its formation. We addressed this problem by activating $4 \beta$-thiobenzylepicatechin (7) with the thiophilic Lewis acid silver tetrafluoroborate $\left(\mathrm{AgBF}_{4}\right)$, thereby coupling it with free phenolic catechin $(2)$ or epicatechin (11). This permitted formation of the interflavanyl bond in procyanidins under essentially neutral and extremely mild $\left(0^{\circ} \mathrm{C}\right)$ conditions ( $\bullet$ Fig. 14$)$ [35], and afforded procyanidins B-1 (12) and B-2 (13) in up to 50\% isolated yields.

The protection of phenolic hydroxy groups of flavan-3-ols with the benzyl functionality often results in disappointingly low 


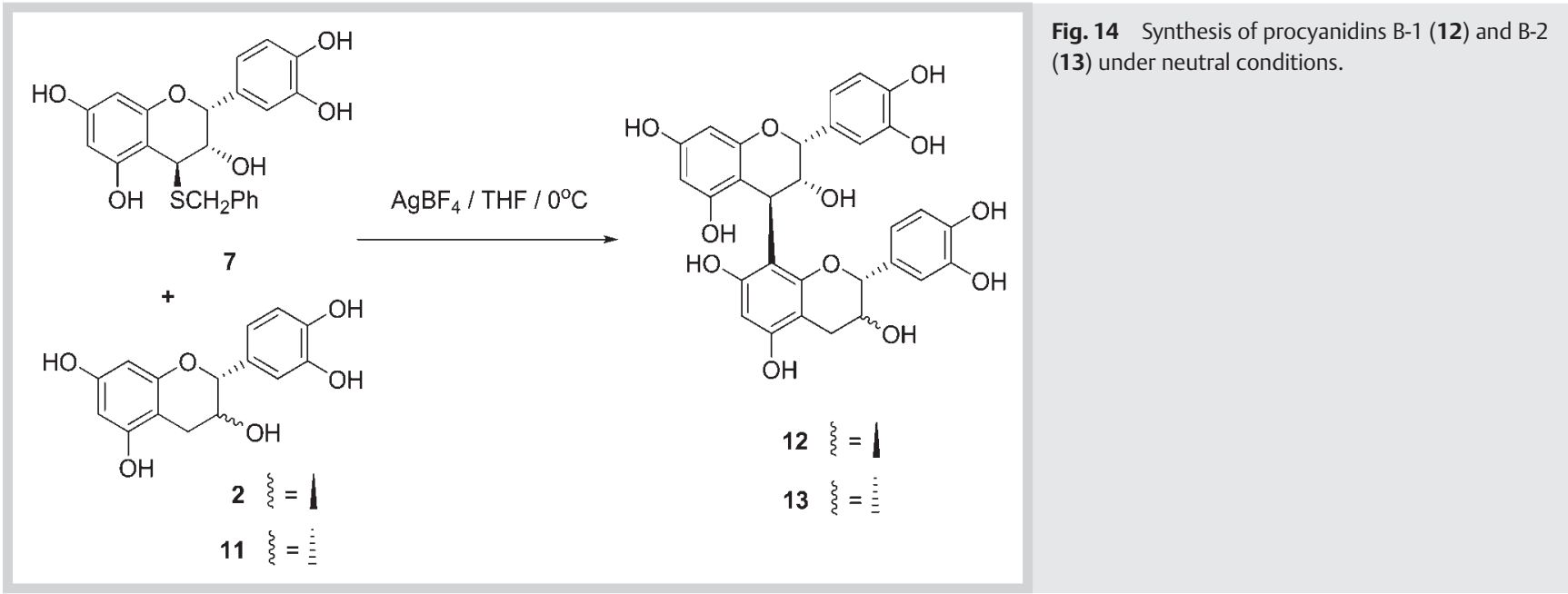

yields ([36], and cited references). In view of the importance of the phenolic per- $O$-benzyl ethers of catechin and epicatechin as building blocks for synthetic procyanidins, we addressed the problem of low yields by capitalizing on the increased acidity of the 4'-hydroxy group of both catechin (2) and epicatechin (11) compared to that of the remaining hydroxy groups [36]. Thus, treatment of catechin (2) and epicatechin (11) with 4.25 molar equivalents of sodium hydride and 5 molar equivalents of benzyl chloride in dry dimethylformamide under $\mathrm{N}_{2}$ at $-78^{\circ} \mathrm{C}$ led to rapid formation of the $4^{\prime}-0$-benzyl ethers 59 and $\mathbf{6 0}$ ( $\odot$ Fig. 15), via a process that can be kinetically controlled. These 4'-O-benzyl derivatives are stable under basic conditions and are not susceptible to $\mathrm{C}$-ring racemization reactions or to the extensive rearrangement reactions via B-ring quinone methides that may form when the 4-hydroxy group is unprotected (see reference [36] for a detailed explanation). When the reaction mixture is allowed to rise to ambient temperatures, the 4 '- $O$-benzyl ethers 59 and 60 are susceptible to clean benzylation of the remaining phenolic hydroxy functions to give the per- 0 -benzyl ethers 61 and 57 in 98 and $90 \%$ isolated yields.

In 1999, Kozikowski and his collaborators published the first [34] of a series of papers $[33,37]$ and patents [38-40] aimed at the development of synthetic strategies for a variety of natural and nonnatural procyanidins which had exhibited significant biological activities. The 3-O-bis-gallate 64 of procyanidin B-2 (13), a cancer cell growth inhibitor, was synthesized via the procedures outlined in 8 Fig. 16. $\mathrm{TiCl}_{4}$-induced coupling of tetra-O-benzylepicatechin (57) with the leucocyanidin derivative 58 (๑ Fig. 12), afforded the procyanidin B-2 per-O-benzyl ether 62 (53\% yield). Procyanidin B-2 (13) was available via catalytic hydrogenation of 62 using $20 \% \mathrm{Pd}(\mathrm{OH})_{2} / \mathrm{C}$ as a catalyst. Galloylation of $\mathbf{6 2}$ using tri-O-benzylgalloyl chloride in pyridine/dimethylaminopyridine (DMAP)(cat) gave the per-O-benzylprocyanidin B-2 diester 63 in near quantitative yield. Hydrogenation over $20 \% \mathrm{Pd}(\mathrm{OH})_{2} / \mathrm{C}$ gave procyanidin B-2 bis-3-O-gallate (64) in $90 \%$ yield. When the $\mathrm{TiCl}_{4}$ used to induce coupling between $\mathbf{5 7}$ and $\mathbf{5 8}$ was replaced by the commercial acidic clay mineral Bentonite $\mathrm{K}-10$, it led to the almost exclusive formation ( $90 \%$ isolated yield) of per- 0 -benzylprocyanidin B-2 (62), without the formation of artifacts like trimeric and/or $(4 \rightarrow 6)$-regioisomeric forms of 62 [37]. The biological activities of the procyanidin bis-gallate $\mathbf{6 4}$ were reviewed by Kozikowski and collaborators [34].

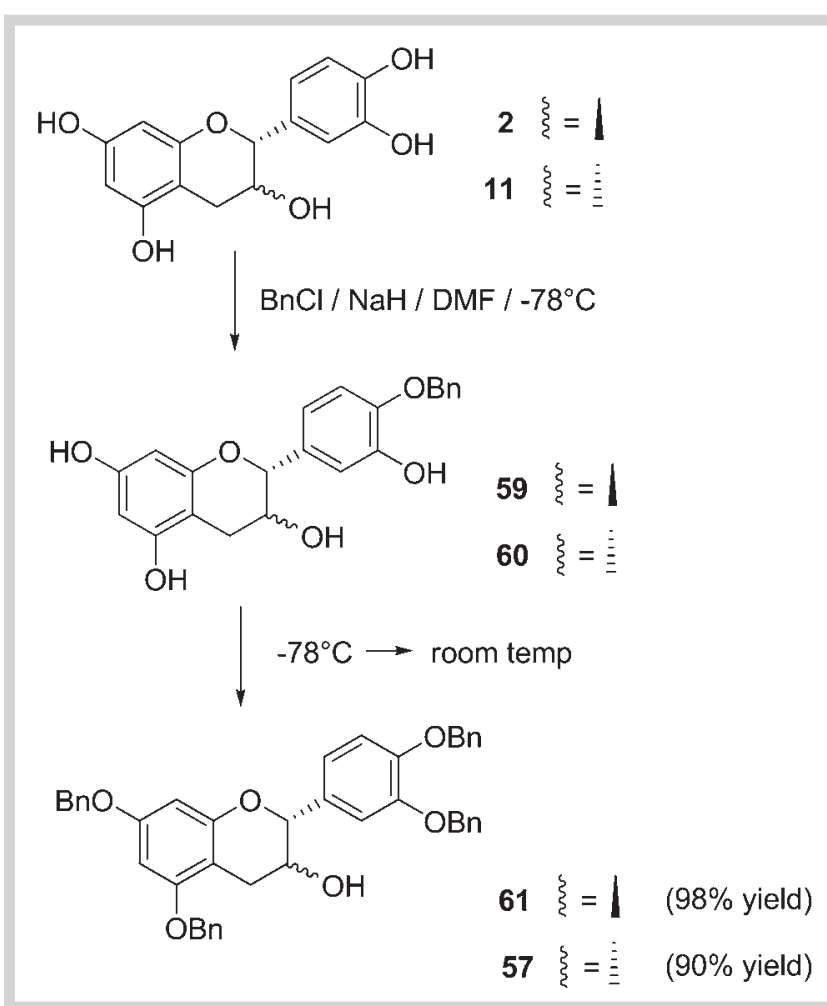

Fig. 15 High-yield process for the phenolic per-O-benzylation of catechin (2) and epicatechin (11).

Kozikowski and coworkers [37] utilized the $\mathrm{AgBF}_{4}$-catalyzed reaction [35] of 4-[(2-benzothiazolyl)-thio]epicatechin (65) with the fully protected procyanidin B-2 derivative 56 to generate a mixture of tri- through octamers (67-72) ( Fig. 17). This mixture was separable by HPLC using a Waters $\mu$ Bondapack $\mathrm{C}_{18}$ column with a solvent gradient consisting of water, ethyl acetate, and acetonitrile. Subsequent deacetylation (40\% aqueous tetra-n-butylammonium hydroxide) and debenzylation (Pearlman's catalyst) afforded the free phenolic forms of procyanidins 67-72, that is, trimer through octamer. Replacement of the dimeric starter unit $\mathbf{6 6}$ in $\odot$ Fig. 17 with the trimeric procyanidin $\mathbf{6 7}$ also afforded 

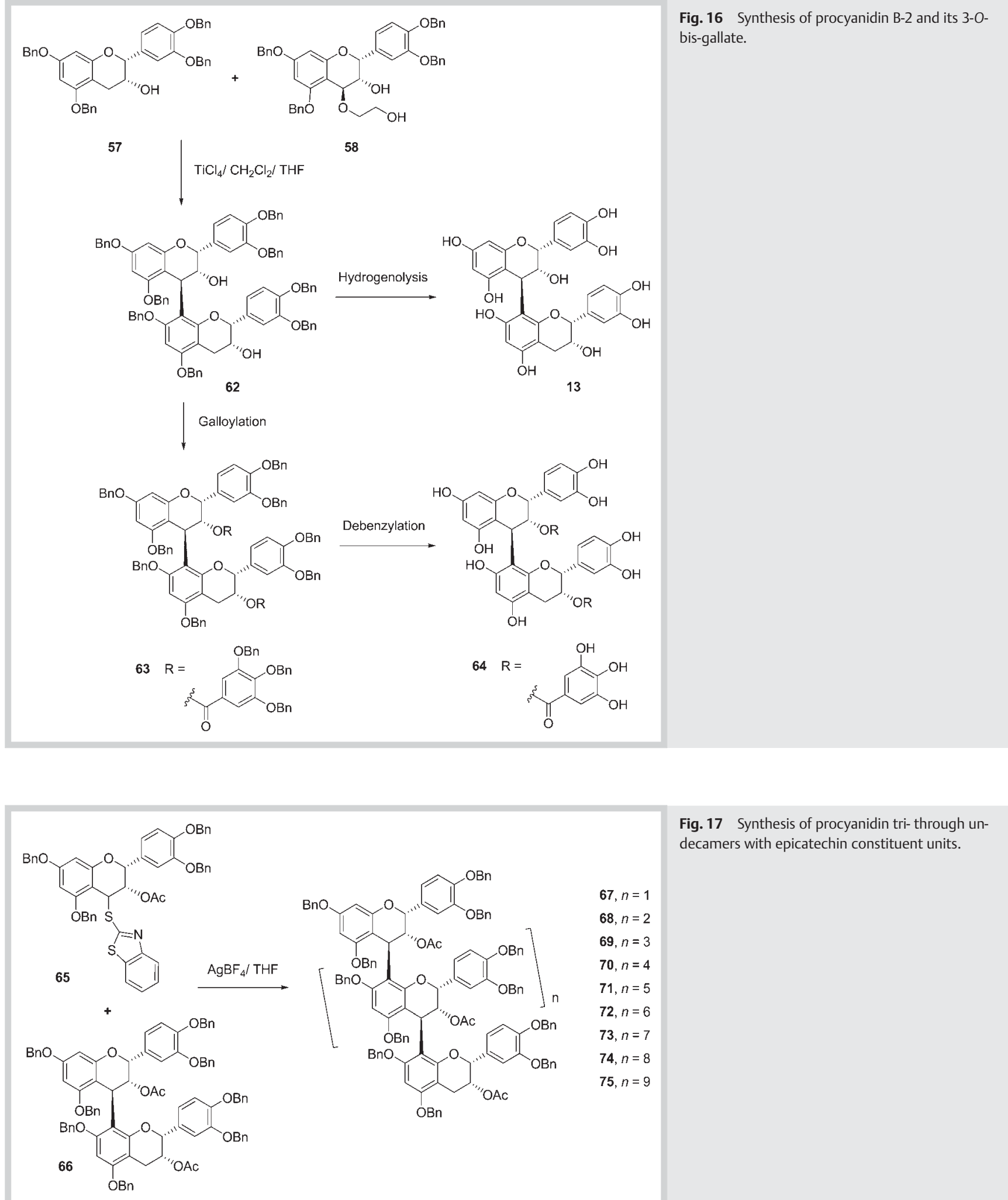

Fig. 17 Synthesis of procyanidin tri- through undecamers with epicatechin constituent units. access to the free phenolic forms of nonamer (73), decamer (74), and undecamer (75).

The synthetic procedures shown in 8 Figs. 16 and 17 gave access to $10-100 \mathrm{mg}$ quantities of some of the procyanidins, allowing assessment of their in vitro biological activities [34,37-40]. In order to fully develop their potential clinical applications, and to address pharmacological and toxicological issues, Sharma and collaborators [41] recently developed the process scale-up conditions necessary for the multigram synthesis of procyanidin B-1 (12) and the 3,3-bis- 0 -gallate (64) of procyanidin B-2 (13). Notable differences from the procedures shown in $\bullet$ Fig. 16, and for the methodology to transform catechin (2) into the much more expensive epicatechin (11) [34], included the benzylation of catechin, refinement of the workup procedure for the Dess-Martin 


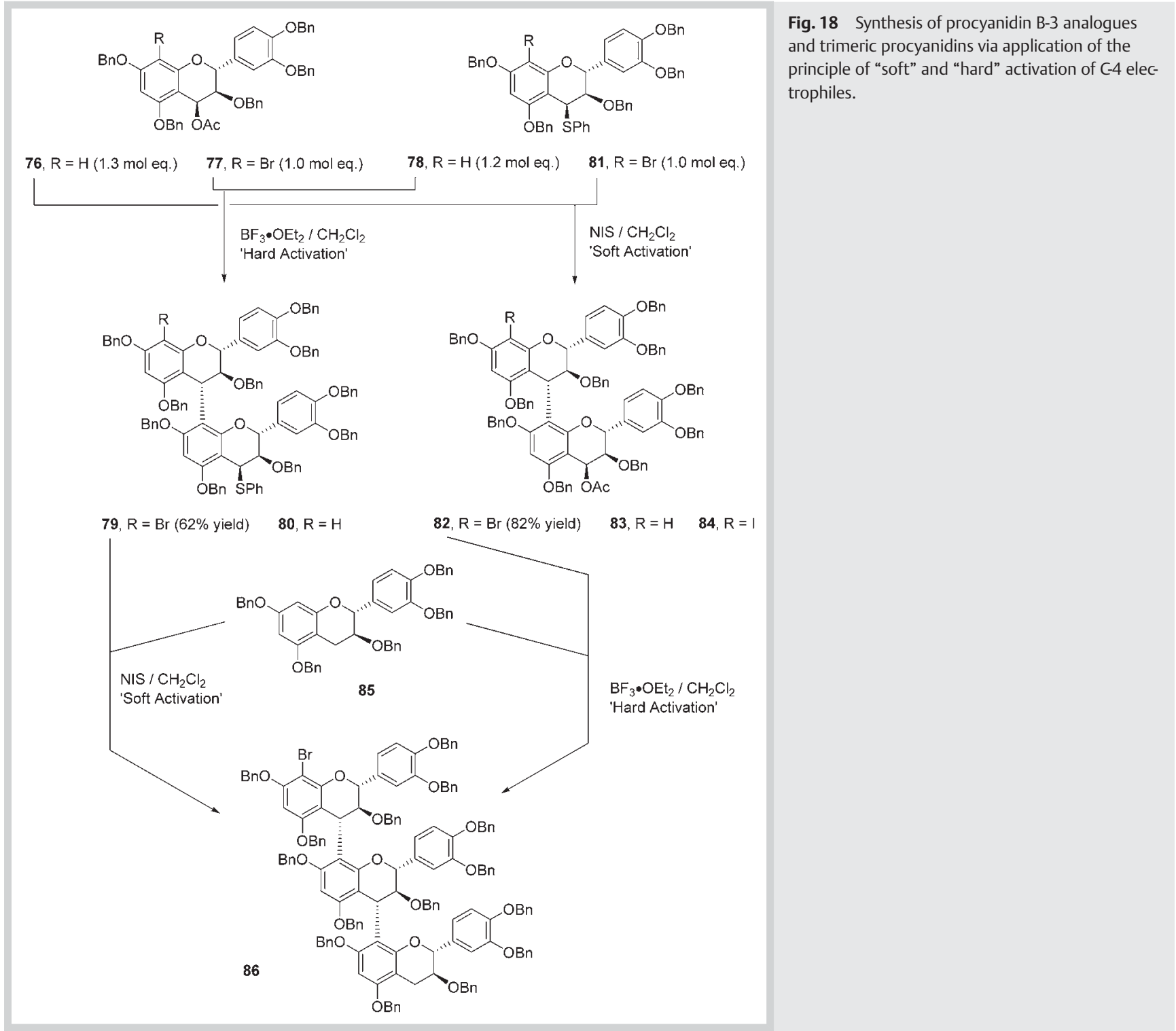

oxidation of per-O-benzylcatechin (61), substituting $\mathrm{TiCl}_{4}$ with Bentonite K-10 clay for the interflavanyl coupling process, and most significantly, using an ethyl acetate/water mixture for the catalytic debenzylation step. This biphasic solvent system permitted preferential dissolution of the per-O-benzylprocyanidin, e.g., 62, in the organic layer, and of the free phenolic compound, such as 13 , in the aqueous layer.

In their "enabling synthetic strategy by orthogonal activation and $C(8)$ protection," Ohmori and coworkers [42] used penta- $O$-benzyl-4 $\beta$ - $O$-acetylcatechin 76 , penta- $O$-benzyl-4 $\beta$-thiophenylcatechin 78, and their C-8 bromo derivatives 77 and 81 to synthesize procyanidin B-3 (14) derivatives, e.g., $\mathbf{8 0}$, and the trimeric bis[catechin- $(4 \alpha \rightarrow 8)$ ]-catechin derivative 86 ( $\odot$ Fig. 18). Utilization of the 8 -bromo- $4 \beta$-acetoxycatechin 77 or the $4 \beta$-phenylsulphide 78 permitted the usage of near equimolar quantities of the electrophilic and nucleophilic moieties. This approach offers an advantage over methods requiring the usage of an excess of the nucleophile in order to limit both self-condensation of the electrophile and random oligomerization of the initially formed procyanidin.
The principle of "soft activation" of the C-4 thiophenyl leaving group in $\mathbf{8 1}$ by $\mathrm{AgBF}_{4}$ or $\mathrm{N}$-iodosuccinimide (NIS), and "hard activation" of the $\mathrm{C}-4$ acetoxy nucleofuge in 77 by $\mathrm{BF}_{3}$. $\mathrm{OEt}_{2}$ to synthesize catechin-related di- and trimeric procyanidins is demonstrated in 0 Fig. 18. Procyanidin B-3 (14) was formed either by soft activation of the $\mathrm{C}-4$ phenylsulphide $\mathbf{7 8}$ with $\mathrm{AgBF}_{4}$ or NIS in the presence of penta- $O$-benzylcatechin (85) (1:3 molar ratio) ( Fig. 18), or by hard activation of the C-4 acetate 76 with $\mathrm{BF}_{3} \cdot \mathrm{OEt}_{2}$ in the presence of 85 (1:3 molar ratio) and subsequent deprotection of the 0 -benzyl groups. However, application of the hard activation procedure employing the 8-bromoacetate $\mathbf{7 7}$ and the 4-phenylsulphide 78 as coupling moieties (1:1.2 molar ratio), or of the soft activation method using the 8-bromophenylsulphide 81 and the C-4 acetate 76 (1:1.3 molar ratio), afforded access to the 8-bromoprocyanidin B-3 analogues 79 and 82 with the requisite $\mathrm{C}-4$ thiophenyl or acetoxy leaving groups, respectively, for further synthetic elaboration. The dimeric 8-debromo analogues 80 and 83 were similarly available by replacing 77 with $\mathbf{7 6}$, and 81 with 78 in the appropriate coupling processes. The dimeric 8-bromophenylsulphide $\mathbf{7 9}$ and 8-bromoacetate 82 were subjected to the same protocol using penta- $O$-benzylcatechin 
(85) as the nucleophile to access the trimeric derivative 86 in good yield. As usual, the free phenolic bis-[catechin- $(4 \alpha \rightarrow 8)]$ catechin was readily available via successive debromination and debenzylation procedures.

Much effort has been devoted to the synthesis of ${ }^{13} \mathrm{C}$ - and ${ }^{14} \mathrm{C}$ labeled catechins and procyanidins. Labeled procyanidin B-3 (14), procyanidin B-6 [catechin- $(4 \alpha \rightarrow 6)$-catechin], procyanidin C-2 \{bis-[catechin- $(4 \alpha \rightarrow 8)$ ]-catechin\}, and a related polymer of high radio-purity were obtained when $\left[\mathrm{U}-{ }^{14} \mathrm{C}\right]$ phenylalanine or $\left[1-{ }^{14} \mathrm{C}\right.$ ]acetate was fed to willow tree shoots [43]. Similar incorporation of $\left[1-{ }^{13} \mathrm{C}\right]$ phenylalanine into cell suspension cultures of Vitis vinifera [44] afforded the ${ }^{13} \mathrm{C}$-labeled anthocyanins, cyanidin-3-O- $\beta$-D-glucopyranoside, peonidin-3- 0 - $\beta$-D-glucopyranoside, and malvidin-3-O- $\beta$-D-glucopyranoside. Nay and his collaborators synthesized rac-4-[ $\left[{ }^{13} \mathrm{C}\right]$ catechin [45], enantiopure 4$\left[{ }^{13} \mathrm{C}\right]$ catechin, and $4-\left[{ }^{13} \mathrm{C}\right]$ epicatechin $[46,47]$, and gram quantities of $4-\left[{ }^{13} \mathrm{C}\right]$ procyanidin B-3 $[48,49]$.

Saito and his coworkers [50] began their synthetic studies of procyanidins by refining the conditions involving the $\mathrm{TiCl}_{4}$-induced coupling of 3-O-acetyltetra-O-benzyl-4 $\beta$-methoxycatechin (87) ( Fig. 19) and tetra-O-benzylcatechin (61) in order to enhance the stereoselective formation of the $(4 \alpha \rightarrow 8)$-interflavanyl bond

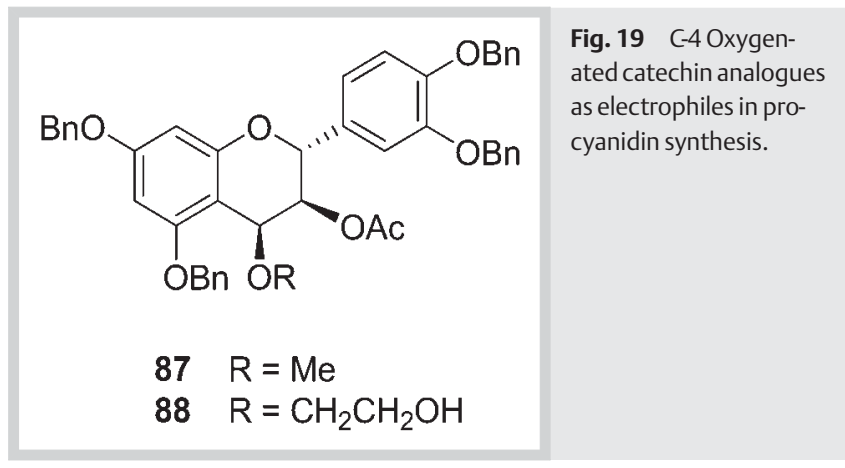

in procyanidin B-3 (14) [50]. The Lewis acid trimethylsilyl trifluoromethane sulphonate (TMSOTf) was used to induce a high degree of stereoselectivity in the formation of the $(4 \alpha \rightarrow 8)$-interflavanyl bond in a gram-scale synthesis of octa- $O$-benzylprocyanidin B-3 using tetra-O-benzylcatechin (61) and per-O-benzyl-

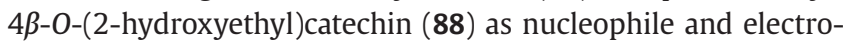
phile, respectively.

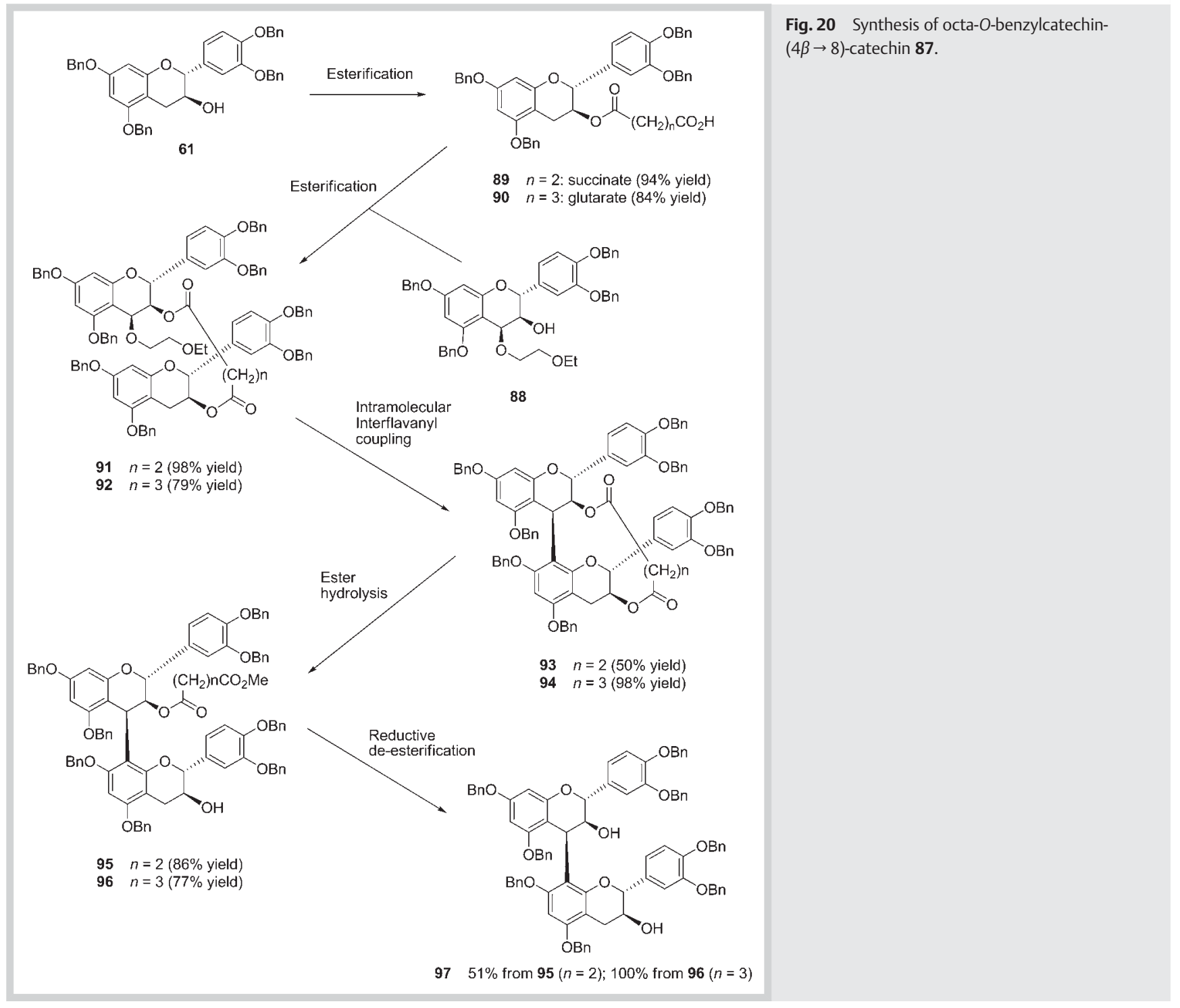




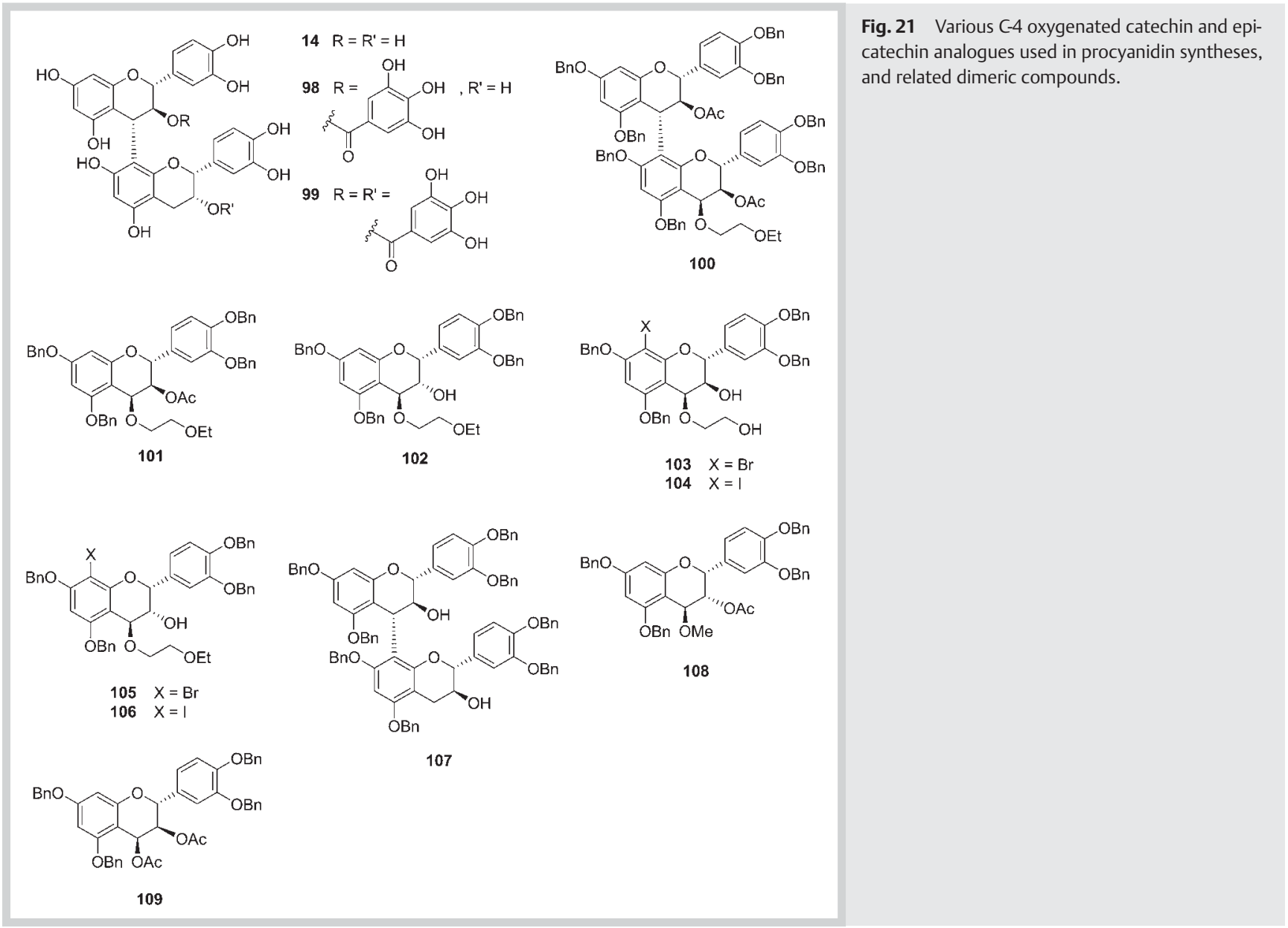

In contrast to the classical approach of interflavanyl bond formation in proanthocyanidins via an intermolecular coupling process, Saito and his coworkers [51] developed a protocol that focused on an intramolecular bond-forming process ( 0 Fig. 20). Esterification of tetra- 0 -benzylcatechin (61) with succinic or glutaric anyhdrides gave the succinate (89) or glutarate (90), respectively. Intermolecular esterification of these esters with the C-4 protected leucocyanidin derivative $\mathbf{8 8}$ using dicyclohexylcarbodiimide (DCC) afforded the heterodimeric esters $\mathbf{9 1}$ and $\mathbf{9 2}$. These were subjected to stereoselective intramolecular interflavanyl bond formation using TMSOTf to afford the dimeric esters 93 and 94. Ester hydrolysis $\left(\mathrm{K}_{2} \mathrm{CO}_{3}\right.$ in methanol) gave the $\mathrm{C}-3$ esters 95 and 96 which were reduced by diisobutylaluminium hydride to give the octa-O-benzyl ether of the $\mathrm{C}-4$ (C-ring) diastereoisomer 97 of procyanidin B-3 (14) in good overall yield.

The protocol shown in 8 Fig. 20 also gave access to the octa- $O$ benzyl ethers of procyanidins B-1 (12), B-2 (13), and B-4 (15) $[52,53]$. The ability of procyanidins B-1 - B-4 and some of their derivatives to inhibit the Maillard reaction was also reported [53]. Substitution of the glutaric ester linker in the heterodimeric ester of type 92 with an azelaic acid [HOOC- $\left(\mathrm{CH}_{2}\right)_{7}-\mathrm{COOH}$ ] unit gave highly stereoselective access to procyanidin B-3 (14) [54]. The Saito group [55] also used TMSOTf-induced intermolecular coupling of tetra- $O$-benzyl-4 $\beta$-O-(2-ethoxyethyl)catechin (88) and tetra- 0 -benzylcatechin (61) or their 3-O-gallates, to obtain procyanidin B-3 (14), its 3-O-gallate 98 , and the bis- $O$-gallate 99 (० Fig. 21). Among these compounds, the bis-O-gallate 99 showed the most potent antioxidant and radical scavenging ac- tivity. Although showing the weakest antioxidant and radical scavenging activity, the mono- 0 -gallate $\mathbf{9 8}$ exhibited the highest inhibition of mammalian DNA polymerase alpha [55]. TMSOTf also effectively induced the stereoselective intermolecular coupling of electrophiles 101 and 102 ( Fig. 21) with octa-O-benzylprocyanidin B-1 - B-4 nucleophiles, and of the dimeric electrophile $\mathbf{1 0 0}$ with the catechin and epicatechin tetra-O-benzyl ethers $\mathbf{6 1}$ and 57, respectively, to give ready access to a series of trimeric procyanidin derivatives [56]. The usual deprotection methods afforded procyanidin C- 1 bis-[epicatechin- $(4 \beta \rightarrow 8)]$ epicatechin\}, procyanidin $\mathrm{C}-2$ \{bis-[catechin- $(4 \alpha \rightarrow 8)]$-catechin\}, bis-[epicatechin- $(4 \beta \rightarrow 8)$ ]-catechin, and epicatechin- $(4 \beta \rightarrow 8)$ catechin- $(4 \alpha \rightarrow 8)$-epicatechin.

A combination of the methods developed by Tueckmantel et al. [34] and Ohmori et al. [42], i.e., protection at C-8 of $4 \beta-O$-(2-hydroxyethyl)catechin or epicatechin as their 8-bromo [103 or 105] or iodo [104 or 106] derivatives ( $\odot$ Fig. 21), and $\mathrm{TiCl}_{4}$-induced coupling with the per-O-benzylethers $\mathbf{6 1}$ and $\mathbf{5 7}$ of catechin and epicatechin, was employed to synthesize procyanidins B-1 - B-4 (12-15) in good yields [57]. Such an approach permitted the coupling of the two monomers in a stoichiometric ratio, and provided a considerable degree of regio- and stereocontrol of the $(4 \rightarrow 8)$ bond formation process, as well as the level of oligomerization. Significantly improved yields and less complicated reaction mixtures were obtained using the 8-bromo derivatives 103 and 105 in place of the 8-iodo analogues 104 and 106. The catalytic deprotection step of, e.g., the 8-bromoprocyanidin B-3 


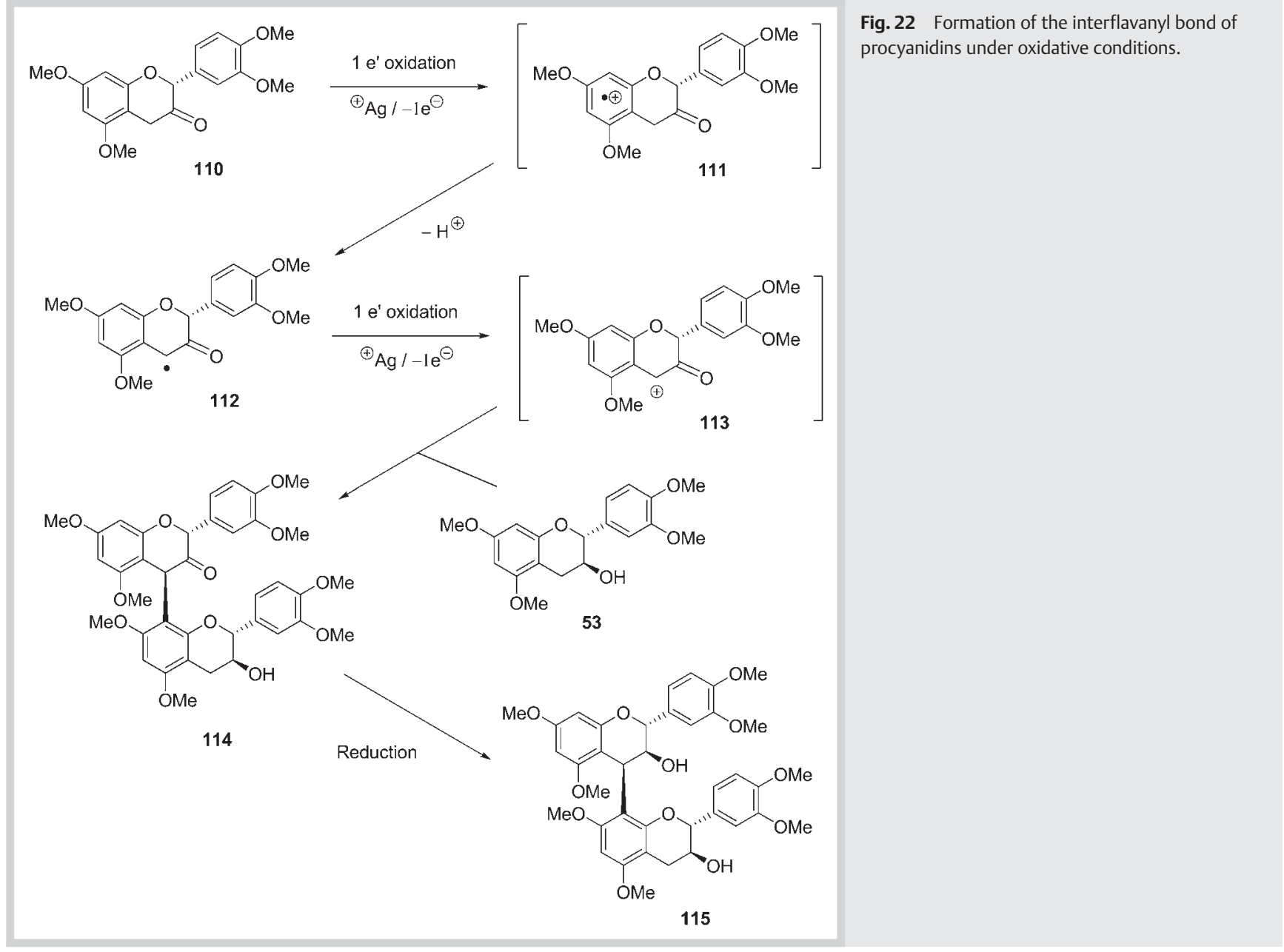

derivative 107 ( $\odot$ Fig. 21) using $\mathrm{Pd}(\mathrm{OH})_{2} / \mathrm{Et}_{3} \mathrm{~N}[58,59]$ led to concomitant reduction of the 8 -bromo bond.

The use of an excess of $\mathrm{TiCl}_{4}$ to induce coupling of the electrophilic and nucleophilic units was improved upon by utilizing the rare earth metal Lewis acid ytterbium III triflate $\left[\mathrm{Yb}(\mathrm{OTf})_{3}\right]$ to catalyze the coupling of tetra-O-benzylcatechin (61) and tetra-Obenzylepicatechin (57), respectively, with the $4 \beta$-methoxyepicatechin derivative 108 [60,61]. The customary deprotection steps afforded procyanidins B-1 (12) and B-2 (13). Procyanidins B-3 (14) and B-4 (15) were similarly accessed via equimolar $\mathrm{Yb}$ (OTf $)_{3}$-induced coupling of the catechin and epicatechin derivatives 61 and 57, respectively, with the $4 \beta$-methoxycatechin derivative $\mathbf{8 7}$, followed by the appropriate deprotection steps.

The versatile protocol of Lewis acid induced coupling of phenolic $O$-protected C-4 functionalized catechin and epicatechin electrophiles like 108 with phenolic 0 -protected catechin and epicatechin nucleophiles like $\mathbf{5 7}$ was expanded to include the use of equimolar amounts of TMSOTf [62] to produce procyanidins up to the tetrameric level. In contrast the tris-(pentafluorophenyl)borane-catalyzed self-condensation of the protected flavan-3,4diacetate 109 ( $\odot$ Fig. 21) led to an intractable mixture that was shown by MALDI-TOF-MS analysis to contain procyanidins of undefined regio- and stereochemistry up to the pentadecameric level.

An innovative method [63] based on the oxidative coupling of tetra- $O$-methyl-3-oxo-catechin (110) and tetra- $O$-methylcatechin (53) was recently developed ( Fig. 22). Treatment of a solu- tion of 110 and 53 with $\mathrm{AgBF}_{4}$ (4 molar equivalents) in THF afforded the 3-oxocatechin- $(4 \beta \rightarrow 8)$-catechin 114 and traces of the $(4 \alpha \rightarrow 8)$-isomer. Reduction of $\mathbf{1 1 4}$ with sodium borohydride in alkaline medium gave the per- $O$-methyl ether of the $\mathrm{C}-4$ (Cring) diastereoisomer 115 of procyanidin B-3 (14). Formation of the 3-oxo analogue 114 may be explained in terms of an initial one-electron oxidation to give an A-ring radical cation 111. Proton loss affords the resonance-stabilized benzylic radical 112 and subsequent conversion into the benzylic carbocation 113 via a second one-electron oxidation step. Stereoselective trapping of carbocation 113 by tetra- $O$-methylcatechin (53) affords the $(4 \beta \rightarrow 8)$-analogue 114 that can be converted into the $C-4$ diastereoisomeric derivative 115 of procyanidin B-3 (14) via metal halide reduction.

\section{Conclusion \\ $\nabla$}

From its humble but pioneering beginnings in the middle 1960s, the subject of proanthocyanidin synthesis has developed to the extent that, today, the vast majority of naturally occurring free phenolic analogues are synthetically accessible on a scale that permits assessment of their pharmacological properties. We have attempted to comprehensively chronicle these early attempts as well as more recent exquisite state-of-the-art methods for inducing interflavanyl bond formation of proanthocyanidin constituent units. This review should not only excite the proanthocyani- 
din expert, but should also be an invaluable reference for young scientists with regards to this complex but fascinating area of research.

\section{References}

1 Roux DG. Recent advances in the chemistry and chemical utilization of the natural condensed tannins. Phytochemistry 1972; 11: 1219-1230

2 Geissman TA, Yoshimura NN. Synthetic proanthocyanidin. Tetrahedron Lett 1966; 24: 2669-2673

3 Drewes SE, Roux DG. Condensed tannins 18 . Stereochemistry of flavan3,4-diol tannin precursors: (+)-mollisacacidin, (-)-leucofisetinidin and (+)-leucorobinetinidin. Biochem J 1964; 90: 343-350

4 Creasy $L L$, Swain T. Structure of condensed tannins. Nature (London) 1965; 208: 151-153

5 Weinges $K$, Perner $J$. The structure of a $\mathrm{C}_{30} \mathrm{H}_{26} \mathrm{O}_{12}$ procyanidin from cola nuts. Chem Commun 1967: 7: 351-352

6 Weinges K, Perner J, Marx HD. Proanthocyanidins, XVI. Synthesis of the octamethyldiacetyl procyanidin B-3. Chem Ber 1970; 103: 2344-2349

7 Haslam E. Biogenetically patterned synthesis of procyanidins. J Chem Soc Chem Commun 1974: 594-595

8 Fletcher AC, Porter LJ, Haslam E, Gupta RK. Plant proanthocyanidins. Part 3. Conformational and configurational studies of natural procyanidins. J Chem Soc [Perkin I] 1977: 1628-1637

9 Thompson RS, Jacques D, Haslam E, Tanner RJN. Plant proanthocyanidins. Part 1. Introduction; the isolation, structure, and distribution in nature of plant procyanidins. J Chem Soc [Perkin I] 1972: 1387-1399

10 Roux DG, Du Preez IC, Rowan AC, Feeney J. Hindered rotation about the $\mathrm{sp}^{2}-\mathrm{sp}^{3}$ hybridized carbon-carbon bond between flavonoid units in condensed tannins. J Chem Soc Chem Commun 1971: 315-316

11 Ferreira D, Hundt HKL, Roux DG. Stereochemistry of a tetraflavanoid condensed tannin from Rhus lancea. J Chem Soc Chem Commun 1971: 1257-1259

12 Botha JJ, Ferreira D, Roux DG. Condensed tannins. Circular dichroism method of assessing the absolute configuration at C-4 of 4-arylflavan3-ols, and stereochemistry of their formation from flavan-3,4-diols. J Chem Soc Chem Commun 1978: 698-700

13 Botha JJ, Young DA, Ferreira D, Roux DG. Synthesis of condensed tannins. Part 1. Stereoselective and stereospecific synthesis of optically pure 4arylflavan-3-ols, and assessment of their absolute stereochemistry at C-4 by means of circular dichroism. J Chem Soc [Perkin I] 1981: 12131219

14 Botha JJ, Ferreira D, Roux DG. Condensed tannins: direct synthesis, structure and absolute configuration of four biflavonoids from Black Wattle Bark ("Mimosa") extract. J Chem Soc Chem Commun 1978: 700-702

15 Botha JJ, Ferreira D, Roux DG. Synthesis of condensed tannins. Part 4. A direct biomimetic approach to [4,6]- and [4,8]-biflavonoids. J Chem Soc [Perkin I] 1981: 1235-1245

16 Young DA, Cronjé A, Botes AL, Ferreira D, Roux DG. Synthesis of condensed tannins. Part 14. Biflavonoid profisetinidins as synthons. The acid-induced "phlobaphene" reaction. J Chem Soc [Perkin I] 1985: 2521-2527

17 Viviers PM, Kolodziej H, Young DA, Ferreira D, Roux DG. Synthesis of condensed tannins. Part 11. Intramolecular enantiomerism of the constituent units of tannins from the Anacardiaceae: stoicheiometric control in direct synthesis: derivation of ${ }^{1} \mathrm{H}$ NMR parameters applicable to higher oligomers. J Chem Soc [Perkin I] 1983: 2555-2562

18 Malan JCS, Young DA, Steynberg JP, Ferreira D. Oligomeric flavanoids. Part 9. The first flavanoids based on mopanol and peltogynol as inceptive electrophiles. J Chem Soc [Perkin I] 1990: 219-225

19 Malan JCS, Steynberg PJ, Steynberg JP, Young DA, Bezuidenhoudt BCB, Ferreira $D$. Oligomeric flavanoids. Part 14 . Proguibourtinidins based on $(-)$-fisetinidol and (+)-epifisetinidol units. Tetrahedron 1990; 46: 2883-2890

20 Coetzee J, Mciteka L, Malan E, Ferreira D. Oligomeric flavanoids. Part 30. Structure and synthesis of butiniflavan-epicatechin and -epigallocatechin probutinidins. Phytochemistry 1999; 52: 737-743

21 Coetzee J, Mciteka L, Malan E, Ferreira D. Structure and synthesis of the first procacinidin dimers based on epicatechin, and gallo- and epigallocatechin. Phytochemistry 2000; 53: 795-804

22 Bennie L, Malan E, Coetzee J, Ferreira D. Structure and synthesis of ether-linked proteracacinidin and promelacacinidin proanthocyanidins from Acacia caffra. Phytochemistry 2000; 53: 785-793
23 Van der Westhuizen JH, Ferreira D, Roux DG. Synthesis of condensed tannins. Part 2. Synthesis by photolytic rearrangement, stereochemistry, and circular dichroism of the first 2,3-cis-3,4-cis-4-arylflavan-3ols. J Chem Soc [Perkin I] 1981: 1220-1226

24 Ding Y, Li X-C, Ferreira D. 4-Arylflavan-3-ols as proanthocyanidin models: absolute configuration via density functional calculations of electronic circular dichroism. J Nat Prod 2010; 73: 435-440

25 Botha JJ, Ferreira D, Roux DG, Hull WE. Condensed tannins: Condensation mode and sequence during formation of synthetic and natural triflavonoids. J Chem Soc Chem Commun 1979: 510-512

26 Botha JJ, Viviers PM, Young DA, Du Preez IC, Ferreira D, Roux DG, Hull WE. Synthesis of condensed tannins. Part 5 . The first angular [4,6:4,8]-triflavonoids and their natural counterparts. J Chem Soc [Perkin I] 1982: 527-533

27 Viviers PM, Young DA, Botha JJ, Ferreira D, Roux DG, Hull WE. Synthesis of condensed tannins. Part 6 . The sequence of units, coupling position and absolute configuration of the first linear [4,6:4,6]-triflavanoid with terminal 3,4-diol function. J Chem Soc [Perkin I] 1982: 535-540

28 Young DA, Ferreira D, Roux DG, Hull WE. Synthesis of condensed tannins. Part 15. Structure of natural "angular" profisetinidin tetraflavanoids: asymmetric induction during oligomeric synthesis. J Chem Soc [Perkin I] 1985: 2529-2535

29 Young DA, Kolodziej H, Ferreira D, Roux DG. Synthesis of condensed tannins. Part 16. Stereochemical differentiation of the first "angular" $(2 S$ $3 R$ )-profisetinidin tetraflavanoids from Rhus lancea (Karee) and the varying dynamic behaviour of their derivatives. J Chem Soc [Perkin I] 1985: 2537-2544

30 Delcour JA, Ferreira D, Roux DG. Synthesis of condensed tannins. Part 9. The condensation sequence of leucocyanidin with (+)-catechin and with the resultant procyanidins. J Chem Soc [Perkin I] 1983: 17111717

31 Delcour JA, Serneels EJ, Ferreira D, Roux DG. Synthesis of condensed tannins. Part 13. The first 2,3-trans-3,4-cis-procyanidins: sequence of units in a "trimer" of mixed stereochemistry. J Chem Soc [Perkin I] 1985: 669-673

32 Steenkamp JA, Ferreira D, Roux DG. Sterospecific functionalization of the heterocyclic ring systems of flavan-3-ol and [4, 8]-biflavan-3-ol derivatives with 2,3-dichloro-5,6-dicyano-1,4-benzoquinone (DDQ). Tetrahedron Lett 1985; 26: 3045-3048

33 Kozikowski AP, Tueckmantel W, George C. Studies in polyphenol chemistry and bioactivity 2. Establishment of interflavan linkage regio- and stereochemistry by oxidative degradation of an $\mathrm{O}$-alkylated derivative

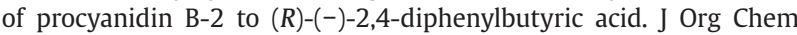
2000; 65: 5371-5381

34 Tueckmantel W, Kozikowski P, Romanczyk LJ. Studies in polyphenol chemistry and bioactivity 1 . Preparation of building blocks from $(+)$-catechin. Procyanidin formation. Synthesis of the cancer cell growth inhibitor, 3-O-galloyl-( $2 R, 3 R)$-epicatechin-( $4 \beta \rightarrow 8)$-[3-O-galloyl-(2R,3R)-epicatechin]. J Am Chem Soc 1999; 121: 12073-12081

35 Steynberg PJ, Nel RJJ, Van Reusburg H, Bezuidenhoudt BCB, Ferreira D. Oligomeric flavanoids. Part 27. Interflavanyl bond formation in procyanidins under neutral conditions. Tetrahedron 1998: 54: 8153-8158

36 Mustafa J, Khan R, Khan IA, Ferreira D. Benzylation of flavan-3-ols (catechins). Org Prep Proced Int 2004; 36: 61-68

37 Kozikowski AP, Tueckmantel W, Bottcher G, Romanczyk LJ. Studies in polyphenol chemistry and bioactivity 4 . Synthesis of trimeric, tetrameric, pentameric, and higher oligomeric epicatechin-derived procyanidins having all- $(4 \beta \rightarrow 8)$-interflavan connectivity and their inhibition of cancer cell growth through cell cycle arrest. J Org Chem 2003; 68: $1641-1658$

38 Tueckmantel W, Kozikowski AP, Romanczyk LJ. Methods for the preparation of catechin and epicatechin dimers. US Patent 2000061547; 2000

39 Romanczyk LJ, Kozikowski AP, Tueckmantel W, Lippman ME. Preparation of polyphenols for use as anticancer agents. US Patent 6207842; 2002

40 Kozikowski AP, Tueckmantel W, Romanczyk LJ, Ma X. Synthesis of oligomeric epicatechin and catechin-derived procyanidins as anticancer agents. US Patent 415616; 2005

41 Sharma PK, Kolchinski AP, Shea HA, Nair IJ, Gou Y, Romanczyk LJ, Schmitz $H H$. Scale-up syntheses of two naturally occurring procyanidins: $(-)$-epicatechin- $(4 \beta \rightarrow 8)-(+)$-catechin and (-)-epicatechin-3-0-galloyl-( $4 \beta \rightarrow 8)-(-)$ epicatechin-3-O-gallate. Org Process Res Dev 2007; 11: $422-430$

42 Ohmori K, Ushimaru N, Suzuki K. Oligomeric catechins: an enabling synthetic strategy by orthogonal activation and $\mathrm{C}(8)$ protection. Proc Natl Acad Sci USA 2004; 101: 12 002-12007 
43 Deprez S, Mila I, Scalbert A. Carbon-14 biolabeling of (+)-catechin and proanthocyanidin oligomers in willow tree cuttings. J Agric Food Chem 1999; 47: 4219-4230

44 Krisa S, Teguo PW, Decendit A, Deffieux G, Vercauteren J, Merillon J-M. Production of ${ }^{13} \mathrm{C}$-labelled anthocyanins by Vitis vinifera cell suspension cultures. Phytochemistry 1999; 51: 651-656

45 Nay B, Arnaudinaud V, Peyrat J-F, Nuhrich A, Deffieux G, Merillon J-M, Vercauteren J. Total synthesis of labeled flavanoids. $2 .{ }^{13} \mathrm{C}$-labeled $( \pm)$ -catechin from potassium $\left[{ }^{13} \mathrm{C}\right]$ cyanide. Eur J Org Chem 2000; 7: $1279-1283$

46 Nay B, Monti J-P, Nuhrich A, Deffieux G, Merillon J-M, Vercauteren J. Methods in synthesis of flavonoids. Part 2: 1 High yield access to both enantiomers of catechin. Tetrahedron Lett 2000; 41: 9049-9051

47 Arnaudinaud V, Nay B, Vercauteren J. Gram-scale production and applications of optically pure $\left[{ }^{13} \mathrm{C}\right]$-labeled $(+)$-catechin and $(-)$-epicatechin. Eur J Org Chem 2001; 12: 2379-2384

48 Arnaudinaud V, Nay B, Verge S, Nuhrich A, Deffieux G, Merillon J-M, Monti J-P, Vercauteren J. Total synthesis of isotopically labeled flavonoids. Part 5: Gram-scale production of ${ }^{13} \mathrm{C}$-labeled (-)-procyanidin B3. Tetrahedron Lett 2001; 42: 5669-5671

49 Arnaudinaud V, Nay B, Nuhrich A, Deffieux G, Merillon JM, Monti J-P, Vercauteren J. Total synthesis of isotopically labeled flavonoids. Part $3:{ }^{13} \mathrm{C}-$ labeled (-)-procyanidin B3 from $1\left[{ }^{13} \mathrm{C}\right]$-acetic acid. Tetrahedron Lett 2001; 42: 1279-1281

50 Saito A, Nakajima N, Tanaka A, Ubukata M. Synthetic studies of proanthocyanidins. Highly stereoselective synthesis of the catechin dimer, procyanidin-B3. Biosci Biotechnol Biochem 2002; 66: 1764-1767

51 Saito A, Nakajima N, Tanaka A, Ubukata M. Synthetic studies of proanthocyanidins. Part 3. Stereoselective 3,4-cis-catechin and catechin condensation by TMSOTf-catalyzed intramolecular coupling method. Tetrahedron Lett 2003; 44: 5449-5452

52 Saito A, Nakajima N, Tanaka A, Ubukata M. Synthetic studies of proanthocyanidins. Part 4. The synthesis of procyanidin B1 and B4: TMSOTf-catalyzed cyclization of catechin and epicatechin condensation. Heterocycles 2003; 61: 287-298

53 Saito A, Nakajima N, Matsuura N, Tanaka A, Ubukata M. Synthetic studies of proanthocyanidins. Part 5. Highly stereoselective synthesis and inhibitory activity of Maillard reaction of 3,4-trans-catechin and epicatechin dimers, procyanidin B1, B2, B3, B4 and their acetates. Heterocycles 2004; 62: 479-489
54 Saito A, Tanaka A, Ubukata M, Nakajima N. Stereoselection of 3,4-cisand 3,4-trans-catechin and catechin condensation under intramolecular coupling method. Synlett 2004; 11: 2040-2042

55 Saito A, Emoto M, Tanaka A, Doi Y, Shoji K, Mizushina Y, Ikawa H, Yoshida $H$, Matsuura N, Nakajima $N$. Stereoselective synthesis of procyanidin B3-3-O-gallate and 3,3"-di-O-gallate, and their abilities as antioxidant and DNA polymerase inhibitor. Tetrahedron 2004; 60: 12 043-12049

56 Saito A, Tanaka A, Ubukata M, Nakajima N. Efficient stereoselective synthesis of proanthocyanidin trimers with TMSOTf-catalyzed intermolecular condensation. Synlett 2004; 6: 1069-1073

57 Tarascou I, Barathieu K, Andre Y, Pianet I, Dufourc E, Fouquet E. An improved synthesis of procyanidin dimers: regio- and stereocontrol of the interflavan bond. Eur J Org Chem 2006; 23: 5367-5377

58 Sajiki H, Kume A, Hattori K, Hirota K. Mild and general procedure for Pd/ C-catalyzed hydrodechlorination of aromatic chlorides. Tetrahedron Lett 2002; 43: 7247-7250

59 Sajiki H, Kume A, Hattori K, Hirota K, Nagase H, Hirota K. Complete and truly catalytic degradation method of PCBs using Pd/C-Et ${ }_{3} \mathrm{~N}$ system under ambient pressure and temperature. Tetrahedron Lett 2002; 43: 7251-7254

60 Mohri Y, Sagehashi M, Yamada T, Hattori Y, Morimura K, Kamo T, Hirota $M$, Makabe $H$. An efficient synthesis of procyanidins. Rare earth metal Lewis acid catalyzed equimolar condensation of catechin and epicatechin. Tetrahedron Lett 2007; 48: 5891-5894

61 Mohri Y, Sagehashi M, Yamada T, Hattori Y, Morimura K, Hamauzu Y, Kamo T, Hirota M, Makabe H. An efficient synthesis of procyanidins using equimolar condensation of catechin and/or epicatechin catalyzed by ytterbium triflate. Heterocycles 2009; 79: 549-563

62 Oyama K-I, Kuwano M, Ito M, Yoshida K, Kondo T. Synthesis of procyanidins by stepwise- and self-condensation using 3,4-cis-4-acetoxy-3-Oacetyl-4-dehydro-5,7,3',4'-tetra-O-benzyl-(+)-catechin and (-)-epicatechin as a key building monomer. Tetrahedron Lett 2008; 49: 31763180

63 Achilonu MC, Bonnet SL, Van der Westhuizen JH. Synthesis of proanthocyanidins. Part 1 . The first oxidative formation of the interflavanyl bond in procyanidins. Org Lett 2008; 10: 3865-3868 